\title{
A Diagnosis Of Stator Winding Fault Based on Empirical Mode Decomposition in PMSMs
}

\author{
R. SELÇUK, Z. DOGAN
}

\begin{abstract}
Stator winding faults may cause severe damages in Permanent Magnet Synchronous Motors (PMSM) if not detected early on. The earliest fault detection in motors should be made during transient states throughout the initial starting period. A new approach based on Empirical Mode Decomposition (EMD) and statistical analysis was presented for detecting stator winding fault by way of transient state phase current of PMSM in this study. Models based on finite elements method were developed for the PMSM representing the healthy and faulty states in order to implement the suggested fault detection method. Afterwards, transient state stator phase winding currents were measured for healthy and faulty states under nominal load in accordance with motor models. These non-linear current signals monitored were separated into its Intrinsic Mode Functions (IMF) via the EMD method. Pearson Correlation Coefficient was used for determining the IMF that most resembles the characteristics of the main signal. Statistical parameter-based feature extractions were carried out for the IMF signals determined for the healthy and faulty states. Fault and fault level detection were carried out successfully by comparing the obtained feature vectors. The acquired results have put forth that the suggested method can be used securely for fault detection in electrical machines especially for early fault detection.
\end{abstract}

Index Terms - Permanent Magnet Synchronous Motors, Stator winding faults, EMD.

\section{INTRODUCTION}

$\mathrm{P}$ ERMANENT MAGNET synchronous motors (PMSMs) are frequently used in various industrial and military applications such as wind energy, electrical vehicles, railroad transportation, military planes etc. due to their various advantages such as high efficiency, high torque, power and flux density, wide speed ranges, long service life, simple structure and precise torque control [1-6]. As is the case for all electrical machines, various faults may develop in PMSMs

RUMEYSA SELÇUK, is with Department of Computer Engineering University of Beykoz University, Istanbul, Turkey, (e-mail:

rumeysaselcuk@beykoz.edu.tr).

iD https://orcid.org/0000-0003-1085-095X

ZAFER DOGAN, is with Department of Electrical Electronics Engineering University of Tokat Gaziosmanpasa, Tokat, Turkey, (e-mail: zafer.dogan@gop.edu.tr).

iD https://orcid.org/0000-0002-7953-0578

Manuscript received November 25, 2019; accepted January 16, 2020. DOI: $\underline{10.17694 / \text { bajece. } 650484}$ due to environmental factors, production and installation faults, long term use under adverse conditions, stator open circuit transformations, thermal, electrical or mechanical strains [2,7]. A fault that develops in motors may result in system shutdown. These shutdowns may lead to loss of production time and raw material. The faults may increase maintenance costs and result in power losses. A minor fault may advance further causing more significant faults [8,9]. Thus, early fault detection is of significant importance for reducing fault ratio and preventing possible problems.

PMSM faults are classified in three groups as mechanical faults, magnetic faults and electrical faults [10]. Statistics indicate that more than $47 \%$ of the electrical motor faults are due to electrical faults [11]. Current studies indicate stator winding faults among the most frequently observed faults in electrical machines including PMSMs. Stator fault is due to the gradual decrease in the insulation between the stator winding threads $[10,12-14]$. The fault detection is the process of detecting and identifying the type and scope of the fault. Typically, a detection process enables the perception or estimation of one or more machinery output such as current [15], [16], voltage [2], [17], vibration [7], [10], and torque [18] by way of sensors. The current signals carrying the fault information are frequently preferred in fault detection processes due to their low cost and ease of access.

Various signal processing methods are used for fault detection in electrical motors. Typical signal processing methods are time domain analysis, frequency domain analysis, time-frequency domain analysis, Park's vector approach [19]. Fast Fourier Transformation (FFT) which is an analysis method at the frequency domain is among the most frequently used signal processing analysis carried out using the harmonic components of the signal as fault feature (FFT) [20]. Since time data is lost during analyses via FFT signal processing method, it is only used for processing fixed signals and sometimes it is difficult to distinguish similar harmonics with this analysis. It is necessary to pass over to the time-frequency domain analysis for overcoming this shortcoming [10,20,21]. Various analysis methods such as Short-time Fourier transformation [22], wavelet transformation [15], Hilbert Huang transformation (HHT) [23], empirical mode decomposition (EMD) have been suggested for timefrequency domain analyses. EMD is an effective method among these other methods for linear and unstable signals $[2$, 24].

There are many studies on winding faults in literature $\mathrm{J}$. Rosero et al. carried out a study analyzing short circuit faults in PMSMs. Intrinsic mode functions (IMFs) were calculated in 
this study via EMD method using the stator current. Afterwards, HHT was applied for calculating the instantaneous frequency values of IMFs. In addition, IMF1 and IMF2 were analyzed using Wigner Ville Distribution (WVD). This study puts forth the capability for determining unstable fault current types for different speed intervals [24]. In their studies, Mejia-Barron et al. presented the application of empirical mode decomposition-based methods such as Ensemble EMD (EEMD) and complete EMD (CEEMD) for inrush current analysis. IMFs were used for focusing on acquiring data on the inter-turn faults in the transformer [25].

Steady state motor currents have been used in majority of the studies in literature in this field for determining PMSM winding faults $[12,15]$. The faster faults are detected in electrical machines, the lower the possible economic losses are. Early stage fault detection in motors is made by way of transient signals monitored during the initial starting time. Because transient durations are on the order of milliseconds. Motor transient current is the best data for this purpose [2628].

The present study puts forth a detection method for stator winding fault in PMSM based on the EMD analysis of Transient Motor Current Signals (TMCSs). Initially, simulation models for the healthy and faulty states of the PMSM were developed in Ansoft Maxwell environment via Finite Elements Method (FEM) and TMCS values were measured under full load conditions. Afterwards, the TMCSs were analyzed via EMD and the IMFs of these currents were calculated. The Pearson Correlation Coefficient (PCC) was then used for determining the IMF that is closest to the main signal. Finally, the statistical characteristics of this determined IMF signal was used for early stage fault detection.

The remainder of this paper is organized as follows. Section 2 presents the FEM simulation model of PMSM for healthy and faulty situations. Section 3 describes the proposed signal analysis and feature extraction. The analysis results obtained in section 4 are given and interpreted in detail. Section 5 is the conclusions section.

\section{PERMAnENT Magnet SynChronous Motor}

Finite elements method (FEM) is a method that enables the examination of the healthy and faulty states of an electrical motor in a computer environment by entering required parameters for that particular motor. It enables performance monitoring without harming the motor since it requires no experiments in a laboratory environment [17]. Maxwell equations are used to solve electromagnetic problems [25]. Thus, the FEM software uses Maxwell equations to reach the solution. Maxwell equalities are provided below [29].

Eq. (1) shows the relationship between electrical field, $E$ and flux density, $J$.

$$
J=\sigma E
$$

The induced field expression is indicated by Eq. (2).

$$
\nabla x E=-\nabla x A
$$

Electrical field is expressed by Eq. (3) in the twodimensional problem.

$$
E=-(A x \nabla V)
$$

Eq. (4) is obtained by placing this electrical field equation in Eq. (1).

$$
I=-\sigma A-\sigma \nabla V
$$

Flux density expression is indicated by (5) according to magnetic vector potential and voltage value gradient.

$$
\nabla x\left(\frac{1}{\mu(B)}\right) \nabla x A=-\sigma A-\sigma \nabla V+J_{\text {source }}
$$

$\mu$, denotes magnetic permeability of the environment, $W$, represents the gradient for the voltage in the area outside the conductive material in two-dimensional magnetic field problems. As such, the amplitude and phase angle values of the value $A$ are calculated.

In the present study, FEM analysis was used to generate a Maxwell 2D model of PMSM since it can put forth a model that is closest to the actual system. Table 1 presents the motor parameters of the designed model and the full model is shown in Fig. 1.

TABLE I

PMSM PARAMETERS DESIGNED WITH FEM

\begin{tabular}{|l|l|}
\hline \multicolumn{2}{|c|}{ PMSM Parameters } \\
\hline Frequency: $50 \mathrm{~Hz}$ & Stator External Diameter: $340 \mathrm{~mm}$ \\
\hline Rated Voltage: $138 \mathrm{~V}$ & Rotor External Diameter: $224 \mathrm{~mm}$ \\
\hline Output Power: $20 \mathrm{~kW}$ & Stator Size: $100 \mathrm{~mm}$ \\
\hline Rated Speed: $1000 \mathrm{rpm}$ & Stator Number of Slots: 36 \\
\hline Number of Poles: 6 & Connection: Star \\
\hline
\end{tabular}

As can be seen from the full model of PMSM, the stator winding type for the motor is whole-coiled. It has a rotor surface mounted magnet with a magnet type of XG196/96.

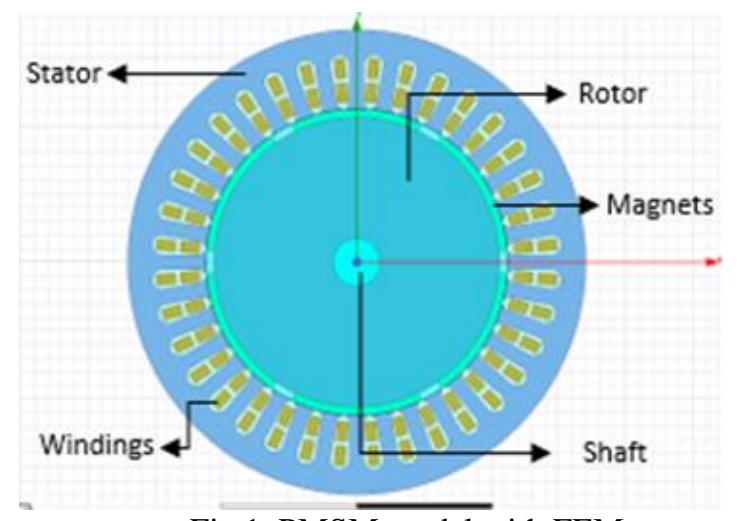

Fig.1. PMSM model with FEM

The 1/6 sampled section of the full model was analyzed in order to keep the analysis time shorter. Fig. 2 presents the PMSM analysis results. 


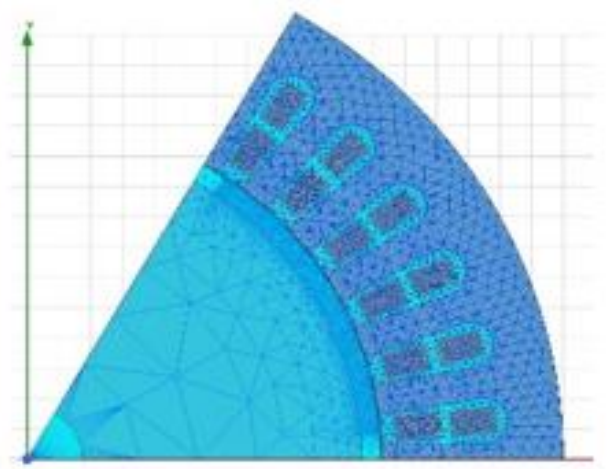

(a)

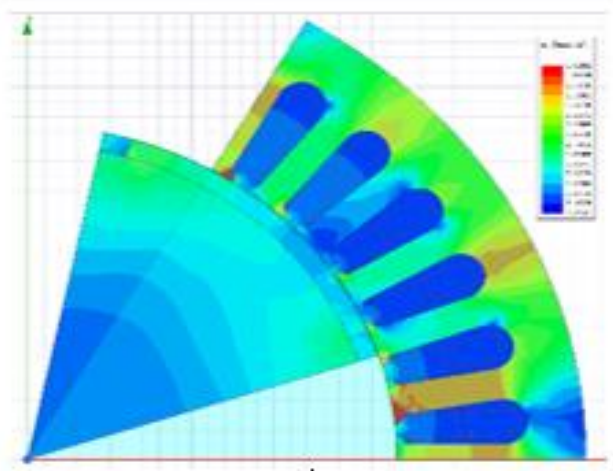

$(b)$

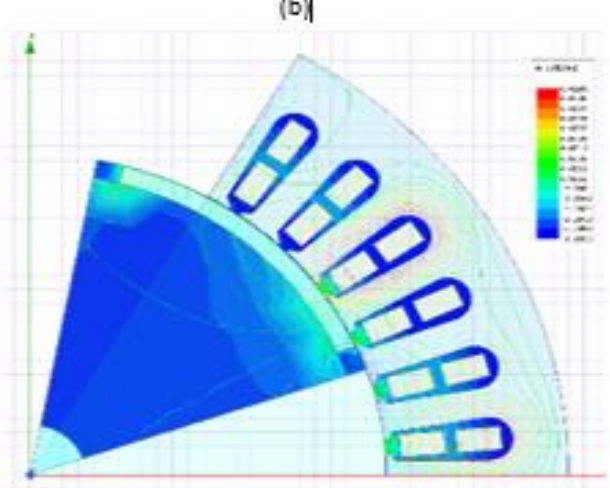

(c)

Fig.2. FEM analysis results of PMSM: a. Mesh structure, b. Magnetic flux density distribution, c. Magnetic flux lines distribution

As can be seen in Fig. 2.a, tetrahedron mesh structure has been used for the FEM based simulation model of the motor. It can be observed from Fig. 2.b indicating the magnetic flux density distribution that $1.368 \mathrm{~T}$ is the maximum magnetic flux density at which the core is unsaturated. Whereas it can be observed in Fig.2.c showing the magnetic flux line distribution that there is proper magnetic flux distribution with proper core geometry.

\section{A. PMSM Inter-turns Fault}

The external circuit shown in Fig. 3 was used to actualize the inter-turn fault in the FEM model of PMSM. As can be seen from the figure, the motor is driven by a 3 phase inverter circuit. The phase winding equivalent resistance changes in the motor equivalent circuit in case of an inter-turn fault. A parallel $R_{\text {fault }}$ resistance was connected to the motor Phase A circuit in order to model this fault in the simulation. The
PMSM inter-turn winding fault was actualized at two different levels in this design. $1^{\text {st }}$ Fault level is F1 and the $2^{\text {nd }}$ Fault level is F2.

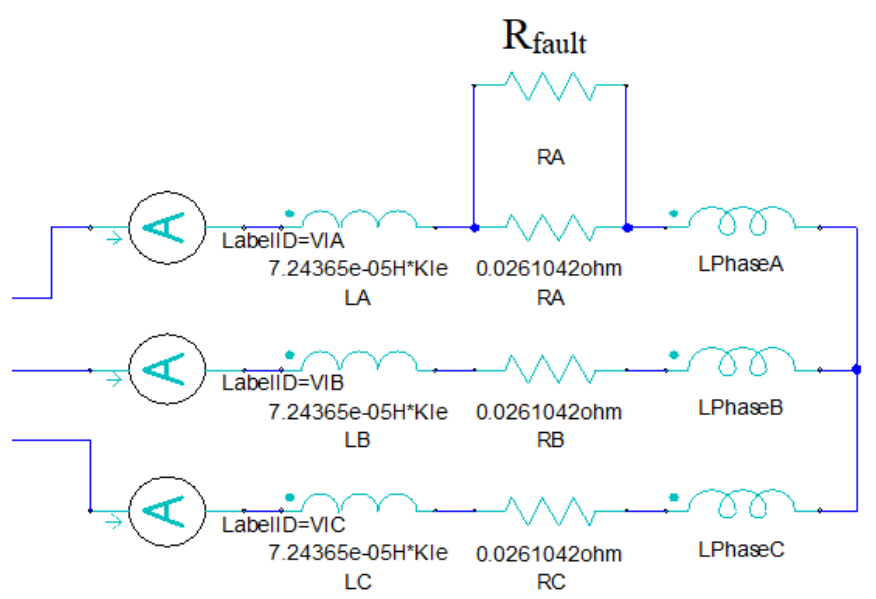

Fig.3. PMSM Inter-turns fault implementation using external circuits

\section{SIGNAL ANALYSIS AND FEATURE EXTRACTION}

The TMCS measured in the simulation model is a nonlinear signal. TMCS was decomposed into its IMFs in this study via EMD, one of the methods used in nonlinear signal analysis. Afterwards, the statistical method of PCC was used for determining which acquired IMF is closest to the main signal. The suggested fault detection algorithm is presented in Fig. 4.

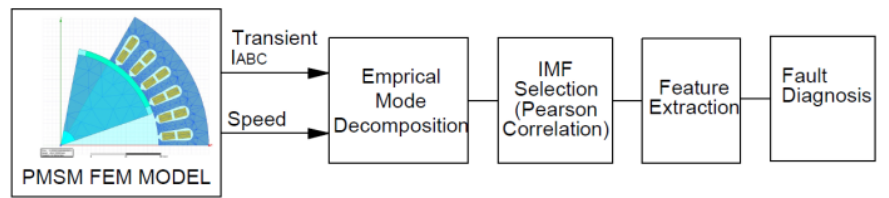

Fig.4. Suggested fault detection algorithm

\section{A. Empirical Mode Decomposition (EMD)}

It is an adaptive method developed for nonlinear and unstable signals. This method decomposes a nonlinear signal into a series of functions comprised of sub-signals known as intrinsic mode function (IMF). The EMD algorithm is shown in Fig. 5.

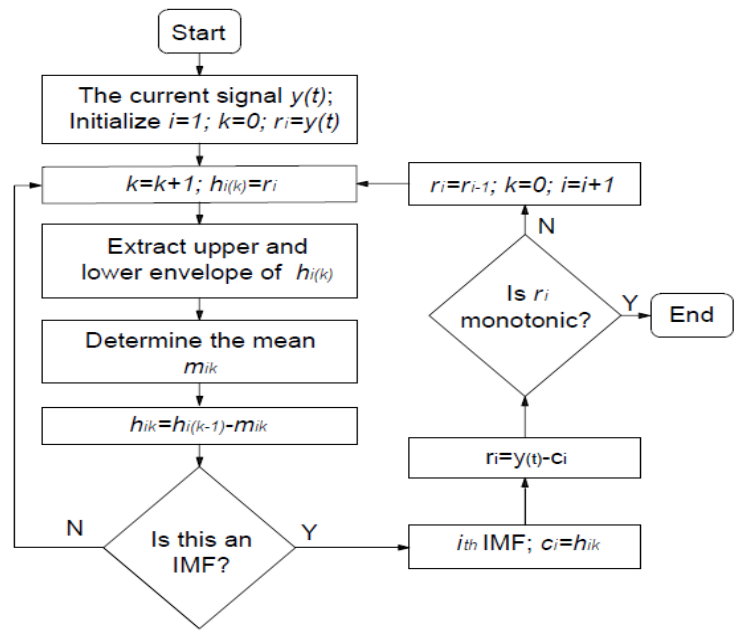

Fig.5. The EMD algorithm 
An IMF function should meet the following two conditions [30]:

(1) The number of extrema and the number of zero-crossings must either be equal or differ at most by one.

(2) At any point, the mean value of the envelope defined by the local maxima and the envelope defined by the local minima should be zero.

A process called sifting should be carried out in order to extract each IMF. First of all, the local maxima and local minima should be determined for the input signal $(y(t))$. Afterwards, cubic spline interpolation function is applied to obtain the upper envelope with the local maxima and the lower envelope with the local minima [31]. The mean of the acquired envelopes is defined by $m_{l}$.

$$
h_{1}=y(t)-m_{1}
$$

If the value of $h_{l}$ obtained as such does not meet the IMF conditions, the process steps are repeated. However, $y(t)$ is replaced by $h_{l}$.

$$
h_{1 k}=h_{1(k-1)}-m_{1 k}
$$

The procedure continues until $h_{1 k}$ meets the IMF conditions. The acquired signal is the first $\operatorname{IMF}\left(c_{l}=h_{l k}\right)$. The step indicated below calculates the residue signal, $r_{l}=y(t)-c_{l}$ and it is controlled whether more IMF than $r_{l}$ can be calculated, that is whether it is a monotonic function or not. If $r_{l}$ is not a monotonic function, the procedure is repeated. However, this time $r_{l}$ replaces $y(t)$ in Eq. (6).

$$
y(t)=\sum_{i=1}^{N} s_{i}(t)+r_{i}(t)
$$

\section{B. Pearson correlation coefficient (PCC)}

After the nonlinear motor circuit signals are decomposed into its IMFs via EMD, the IMF signal with features closest to the main signal should be determined. PCC is one of the statistical methods that is most frequently used to determine the relationship between two different signals and it is also a measure of the linear correlation between two variables [32]. The covariance of the two variables in this correlation method is divided by the product of their standard deviations in this method. $r$, denotes the correlation coefficient and its mathematical formula is expressed by Eq. (9).

$$
r=\frac{\sum x_{i} y_{i}-\frac{\sum x_{i} \sum y_{i}}{n}}{\sqrt{\left(\sum x_{i}^{2}-\frac{\left(\sum x_{i}\right)^{2}}{n}\right)} \sqrt{\left(\sum y_{i}^{2}-\frac{\left(\sum y_{i}\right)^{2}}{n}\right)}}
$$

The coefficient varies between -1 and 1 . Coefficients that are close to -1 indicate a negative relationship between the variables, whereas coefficients that are close to 1 indicate a positive relationship whereas the value of 0 indicates that there is no relationship between the variables.

\section{Feature extraction}

Extracting the features of the signal is one of the most important stages for fault detection. Using statistical parameters such as standard deviation, variance and mean value is a practical method for the analysis of stable signals in the time dimension.

The variance of a variable represents its distance from the arithmetic mean and is expressed by Eq. (10). In this equation, $\sigma^{2}$, denotes the variance, $n$, is the number of elements in the series, $x$, is the series element and $\bar{x}$ represents the arithmetic mean of the numbers in the series.

$$
\sigma^{2}=\frac{1}{n-1} \sum_{i=1}^{n}\left(x_{i}-\bar{x}\right)^{2}
$$

Standard deviation can be expressed as the measure of the variation or fluctuation in the data set. It is frequently denoted by the symbol $\sigma$. Standard deviation is calculated by taking the square root of the variance. The standard deviation formula is presented in Eq. (11).

$$
\sigma=\sqrt{\frac{1}{n-1} \sum_{i=1}^{n}\left(x_{i}-\bar{x}\right)^{2}}
$$

\section{RESULTS AND DISCUSSIONS}

The TMCS and motor speed were measured from the designed model for the healthy and faulty states at nominal load in order to examine the impacts of motor winding fault. Fig. 6 shows the transient currents and speed for the motor

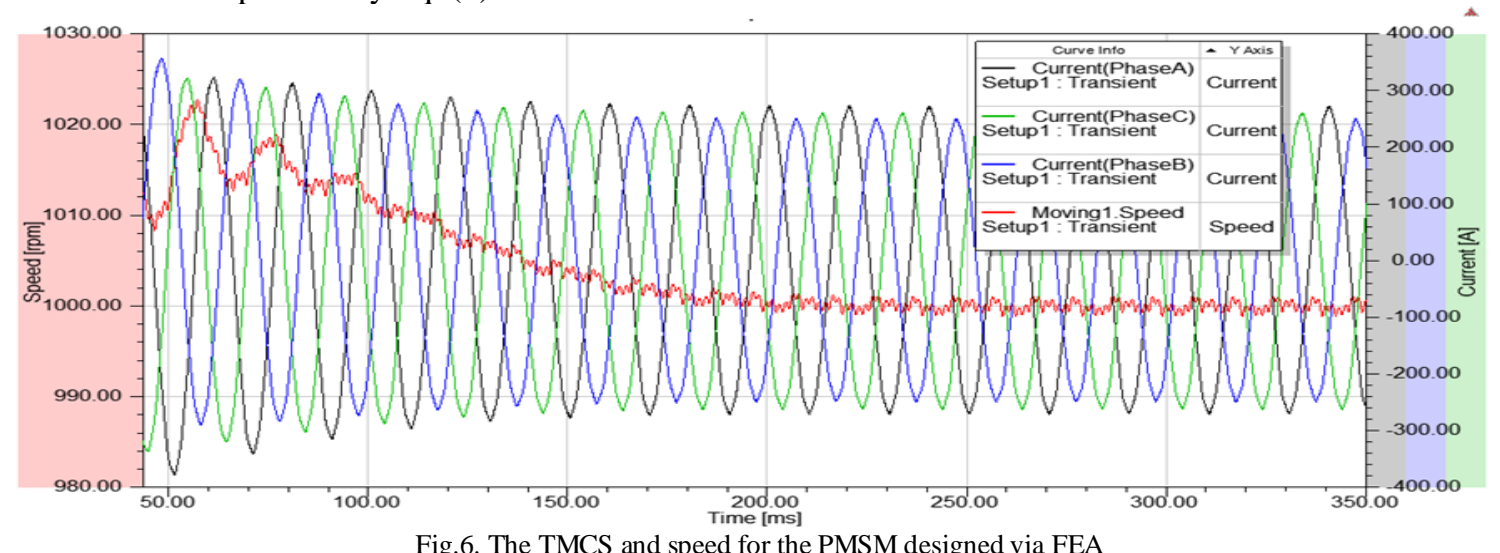

Fig.6. The TMCS and speed for the PMSM designed via FEA

The transient state that makes up the initial starting duration of the PMSM ends when the motor reaches the synchronous speed. As can be seen from Fig. 6, the motor reaches the synchronous speed of $1000 \mathrm{rpm}$ at $310 \mathrm{~ms}$ and the motor circuits become stable. The comparative graphs for the healthy and faulty state TMCS of the motor are presented in Fig. 7. 


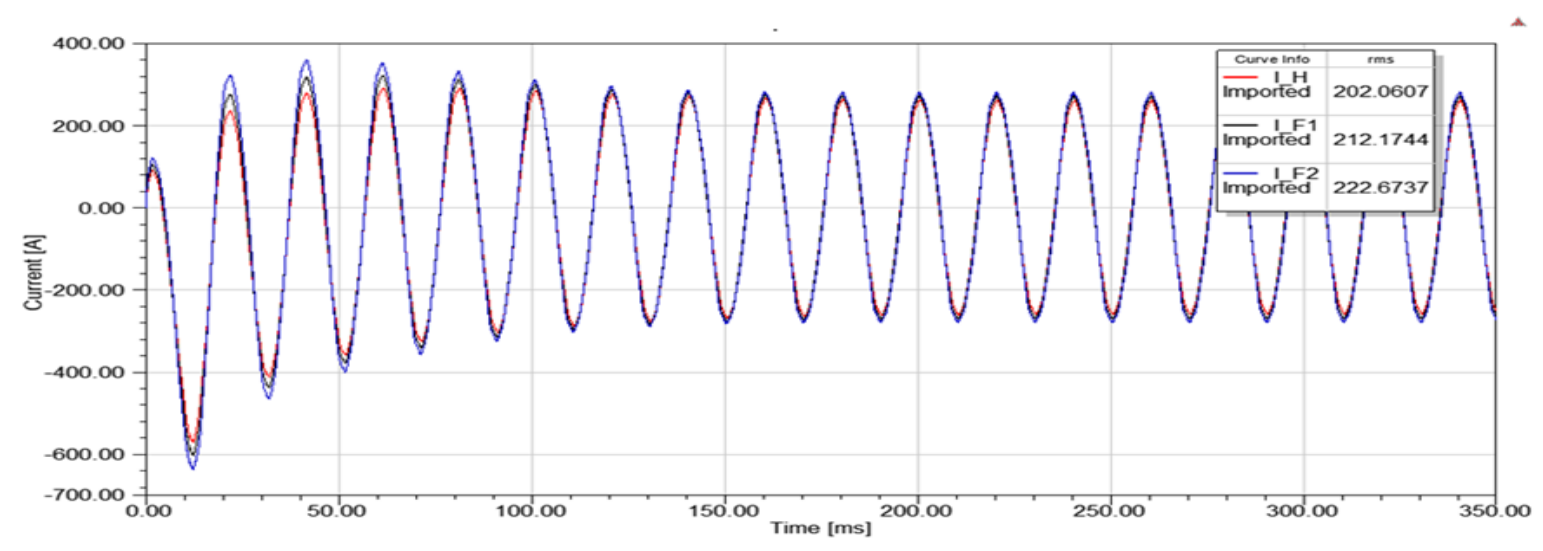

Fig.7. The TMCS for the healthy and F1, F2 faulty states of the motor

As can be seen from Fig. 7, the rms values of the motor TMCS in healthy, F1 and F2 states are $202.06 \mathrm{~A}, 212.17 \mathrm{~A}$ and 222.67 A respectively. The currents drawn by the motor increases with increasing fault level. Fig. 8 presents the IMFs obtained by decomposing via EMD the nonlinear motor TMCS for the healthy, F1 and F2 states of the motor shown in Fig.7.

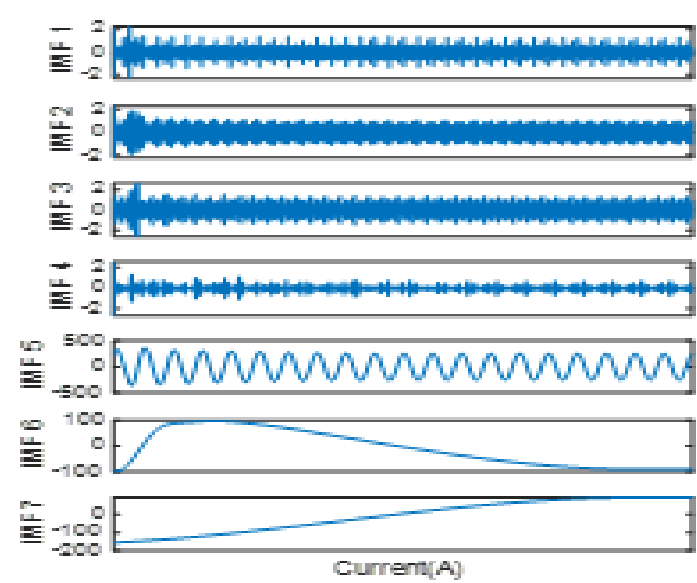

[a]

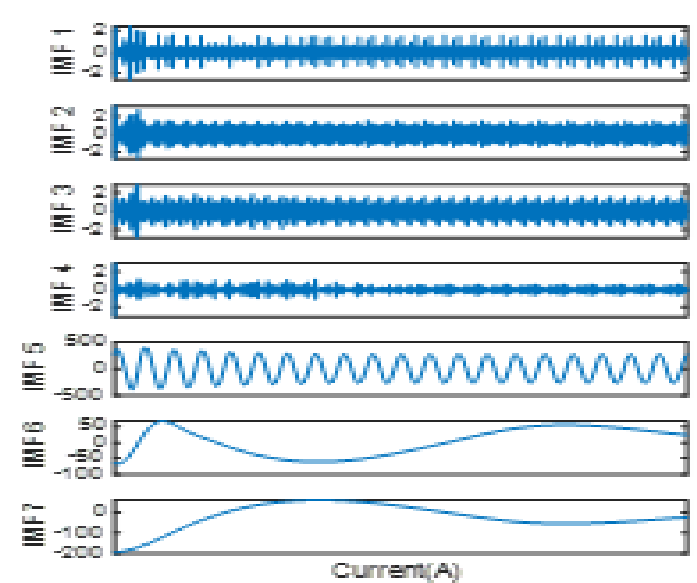

(b)

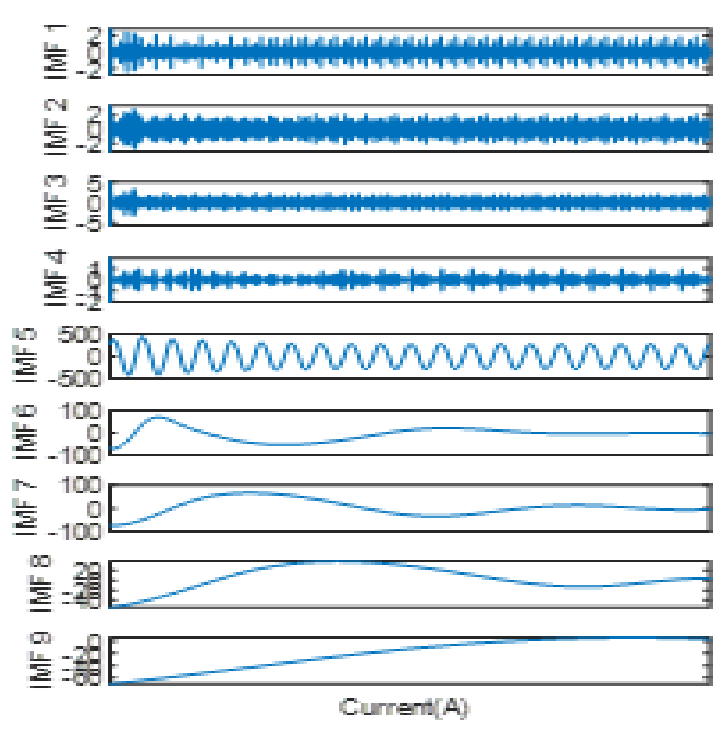

(c)

Fig.8. The EMDs of TMCSs: a). Healthy state IMFs, b). F1 fault state IMFs, c). F2 fault state IMFs. 
According to the graphs in Fig. 8, the residual signal has been reached at the EMD $6^{\text {th }}$ iteration (IMF6) for the healthy and F1 fault states, whereas the residual signal has been reached at the $7^{\text {th }}$ iteration (IMF7) for the F2 fault state. It is difficult to visually determine the IMF representing the main signals for all three states. Hence, these IMFs were analyzed via PCC method for determining the relationship between the main signals and the IMFs and the results shown in Fig. 9 have been obtained.

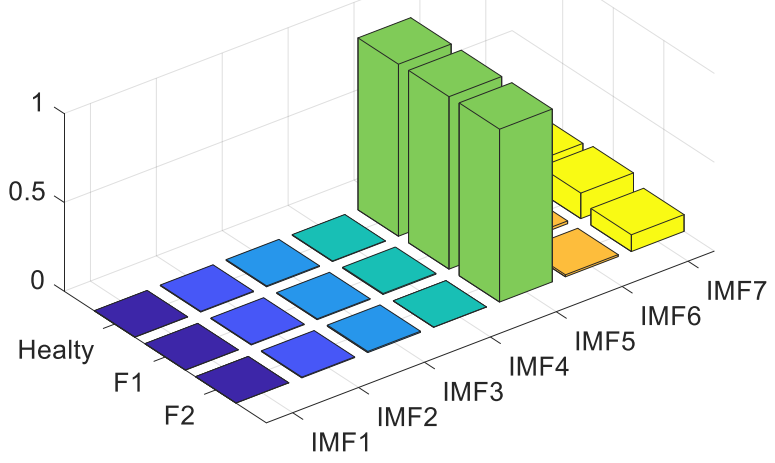

Fig.9. Correlation coefficients for the IMFs calculated for the healthy, F1 and F2 states

As an approach, it can be considered in EMD decompositions that the IMF1 obtained at the end of the 1st iteration is closest to the main signal. However, this approach may not always be correct. As can be seen from Fig. 9, since the correlation coefficients for IMF1, IMF2, IMF3, IMF4 and IMF6 are in the 0.0016684-0.007135 interval for all three states of healthy, F1 and F2; these IMFs have almost no relationship with the main signal. The correlation coefficients for IMF5 are 0.96834, 0.97077 and 0.97304 in the healthy, F1 and F2 states respectively. As can be seen, IMF5 is the signal that is closest to the main signal for all three states. Thus, information can be obtained on the motor state carried by the nonlinear main signals by way of statistical analyses of the IMF5s.

Fig. 10 presents the histograms for the statistical parameters of the IMF5 signals representing the healthy, F1 and F2 states. Whereas the variance value observed in this figure is 39034,2 for the healthy state, it is 43334.1 for the F1 state and 48049.1 for the F2 state. This value has increased from the healthy state with the increase in fault level. These changes are similar for the standard deviation and mean value parameters. The motor inter-turn winding fault and fault level can be easily determined by taking these changes into consideration.

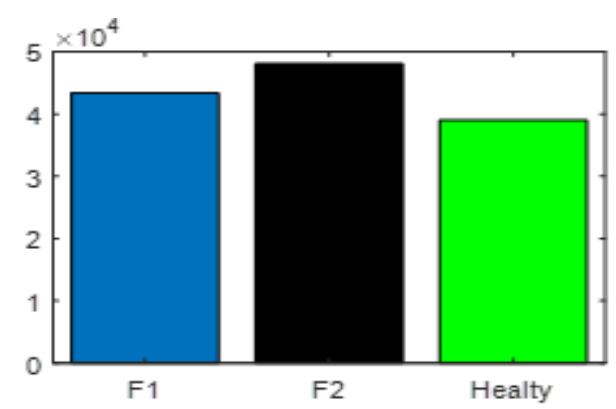

(a)

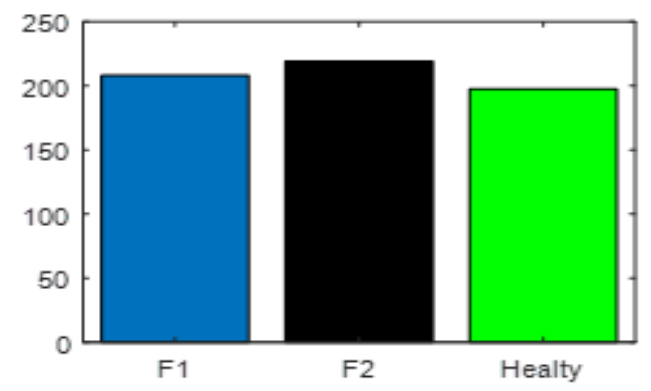

(b)

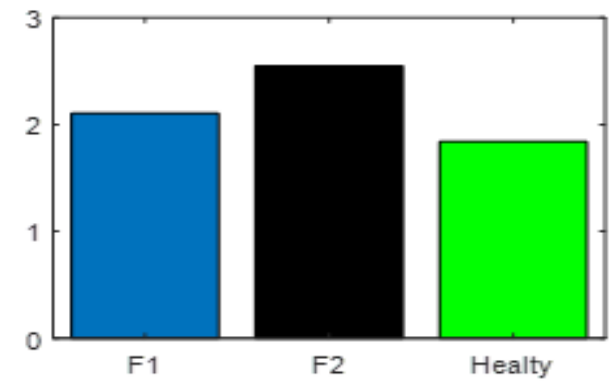

(c)

Fig.10. Statistical parameters of the IMF5: a) Variance histogram, b). Standard deviation histogram, c). Mean value histogram

\section{CONCLUSIONS}

Early fault detection in motors should be carried out in temporary states during the initial starting period. In this study, a new approach based on the signal processing method of EMD and statistical analysis for winding fault detection in PMSMs using temporary state phase current.

Healthy and faulty states PMSM models were generated by using FEM. TMCS and motor speed signals were acquired by way of the designed models. The acquired signals were decomposed into their IMFs via the EMD method. At the end of the decomposition, 7 IMFs were calculated for the healthy state and F1 fault state and 9 IMFs for the F2 fault state. PCC was used for determining the IMF from among the decomposed IMFs that can represent the main signal with TMCS. It was observed for all three of the healthy and faulty states that IMF5 overlaps with the main signal with correlation coefficients of around 0.9. Fault detection and fault level detection were carried out successfully by way of statistical analyses on IMF5 signals in the healthy and faulty states. The acquired results indicate that the suggested method can be preferred for early detection of inter-turn winding faults in electrical machines. 


\section{REFERENCES}

[1] S. S. Moosavi, A. Djerdir, Y. A. Amirat, and D. A. Khaburi, "Demagnetization fault diagnosis in permanent magnet synchronous motors: A review of the state-of-the-art," J. Magn. Magn. Mater., vol. 391, pp. 203-212, 2015.

[2] H. Li, J. Hang, J. Fang, P. Zhang, S. Ding, and Q. Wang, "Inter-turn fault diagnosis of permanent magnet synchronous machine based on variational mode decomposition," Proc. 13th IEEE Conf. Ind. Electron. Appl. ICIEA 2018, pp. 24222425, 2018.

[3] J. C. Urresty, J. R. Riba, and L. Romeral, "Diagnosis of interturn faults in pmsms operating under nonstationary conditions by applying order tracking filtering," IEEE Trans. Power Electron., vol. 28, no. 1, pp. 507-515, 2013.

[4] H. Lee, H. Jeong, and S. W. Kim, "Diagnosis of Interturn Short-Circuit Fault in PMSM by Residual Voltage Analysis," SPEEDAM 2018 - Proc. Int. Symp. Power Electron. Electr. Drives, Autom. Motion, pp. 160-164, 2018.

[5] L. ERGENE and C. EKINN, "Cross Saturation Inductance Analysis of a Permanent Magnet Synchronous Motor," Balk. J. Electr. Comput. Eng., vol. 6, no. 3, pp. 8-13, 2018.

[6] Y. B. Yakut, S. Sünter, and M. Özdemir, "Simulation of Matrix Converter-Fed Permanent Magnet Synchronous Motor With Neural Fuzzy Controller," vol. 6, no. 2, 2016.

[7] J. Härsjö, Modeling and Analysis of PMSM with TurnTo-Turn Fault. 2016.

[8] S. Moon, H. Jeong, H. Lee, and S. W. Kim, "Interturn short fault diagnosis in a PMSM by voltage and current residual analysis with the faulty winding model," IEEE Trans. Energy Convers., vol. 33, no. 1, pp. 190-198, 2018.

[9] H. Jeong, S. Moon, J. Lee, and S. W. Kim, "Inter-turn short fault diagnosis of permanent magnet synchronous machines using negative sequence components," Proceedings of the IEEE International Conference on Industrial Technology. pp. 170-174, 2016.

[10] H. Liang, Y. Chen, S. Liang, and C. Wang, "Fault Detection of Stator Inter-Turn Short-Circuit in PMSM on Stator Current and Vibration Signal," Applied Sciences, vol. 8, no. 9. p. 1677, 2018.

[11] Y. Maanani and A. Menacer, "Modeling and Diagnosis of the Inter-Turn Short Circuit Fault for the Sensorless InputOutput Linearization Control of the PMSM," Period. Polytech. Electr. Eng. Comput. Sci., vol. 63, no. 3, pp. 159-168, 2019.

[12] A. Mohammed, J. I. Melecio, and S. Djurović, “OpenCircuit Fault Detection in Stranded PMSM Windings Using Embedded FBG Thermal Sensors," IEEE Sens. J., vol. 19, no. 9, pp. 3358-3367, 2019.

[13] G. C. Stone, "Condition monitoring and diagnostics of motor and stator windings - A review," IEEE Trans. Dielectr. Electr. Insul., vol. 20, no. 6, pp. 2073-2080, 2013.

[14] T. J. Kang, J. Hong, S. Bin Lee, Y. W. Yoon, D. H. Hwang, and D. Kang, "The influence of the rotor on surge pd testing of low voltage AC motor stator windings," IEEE Trans. Dielectr. Electr. Insul., vol. 20, no. 3, pp. 762-769, 2013.

[15] C. Chuang, Z. Wei, W. Zhifu, and L. Zhi, "The Diagnosis Method of Stator Winding Faults in PMSMs Based on SOM Neural Networks," Energy Procedia, vol. 105, pp. 2295-2301, 2017.
[16] L. Otava, "Implementation of PMSM Inter-turn Short Fault Detection Using Frequency Analysis of Stator Currents," IFAC-PapersOnLine, vol. 49, no. 25, pp. 86-91, 2016.

[17] J. C. Urresty, J. R. Riba, and L. Romeral, “Application of the zero-sequence voltage component to detect stator winding inter-turn faults in PMSMs," Electr. Power Syst. Res., vol. 89, pp. 38-44, 2012.

[18] M. Fitouri, Y. Bensalem, and M. N. Abdelkrim, "Modeling and detection of the short-circuit fault in PMSM using Finite Element Analysis," IFAC-PapersOnLine, vol. 49, no. 12, pp. 1418-1423, 2016.

[19] S. Liang, Y. Chen, H. Liang, and X. Li, "Sparse representation and SVM diagnosis method inter-turn shortcircuit fault in PMSM,” Appl. Sci., vol. 9, no. 2, 2019.

[20] T. Yang, H. Pen, Z. Wang, and C. S. Chang, "Feature Knowledge Based Fault Detection of Induction Motors Through the Analysis of Stator Current Data," IEEE Trans. Instrum. Meas., vol. 65, no. 3, pp. 549-558, 2016.

[21] Y. Chen, S. Liang, W. Li, H. Liang, and C. Wang, "Faults and diagnosis methods of permanent magnet synchronous motors: A review," Appl. Sci., vol. 9, no. 10, 2019.

[22] E. G. Strangas, S. Aviyente, and S. S. H. Zaidi, "Timefrequency analysis for efficient fault diagnosis and failure prognosis for interior permanent-magnet AC motors," IEEE Trans. Ind. Electron., vol. 55, no. 12, pp. 4191-4199, 2008.

[23] S. Ahsanullah, Kazi; Jeyasankar, Elango; Panda, S. K. ; Shanmukha, Ramakrishna; Nadarajan, "Detection and Analysis of Winding and Demagnetization Faults in PMSM based Marine Propulsion Motors" 2017 IEEE International Electric Machines and Drives Conference (IEMDC), pp. 1-7, 2017.

[24] Y. Yang, J. Cheng, and K. Zhang, "An ensemble local means decomposition method and its application to local rubimpact fault diagnosis of the rotor systems," Meas. J. Int. Meas. Confed., vol. 45, no. 3, pp. 561-570, 2012.

[25] J. Rosero, L. Romeral, J. A. Ortega, and E. Rosero, "Short circuit fault detection in PMSM by means of empirical mode decomposition (EMD) and wigner ville distribution (WVD)," Conf. Proc. - IEEE Appl. Power Electron. Conf. Expo. - APEC, pp. 98-103, 2008.

[26] A. Mejia-Barron, M. Valtierra-Rodriguez, D. GranadosLieberman, J. C. Olivares-Galvan, and R. Escarela-Perez, "The application of EMD-based methods for diagnosis of winding faults in a transformer using transient and steady state currents," Meas. J. Int. Meas. Confed., vol. 117, pp. 371-379, 2018.

[27] V. T. Tran, R. Cattley, A. Ball, B. Liang, and S. Iwnicki, "Fault diagnosis of induction motor based on a novel intelligent framework and transient current signals," Chem. Eng. Trans., vol. 33, pp. 691-696, 2013.

[28] J. A. Antonino-Daviu, A. Quijano-Lopez, V. FusterRoig, and C. Nevot, "Case stories of induction motors fault diagnosis based on current analysis," Pet. Chem. Ind. Conf. Eur. Conf. Proceedings, PCIC Eur., pp. 1-9, 2016.

[29] H. Douglas and P. Pillay, "The impact of wavelet selection on transient motor currefnt signature analysis," 2005 IEEE Int. Conf. Electr. Mach. Drives, pp. 80-85, 2005. 
[30] .M, Tezcan. İ, Çanakoğlu., "Asenkron Motorlarda Kırık Rotor Barı Arızalarının Sonlu Elemanlar Yöntemi ile İncelenmesi", IATS' 09, Uluslarası İleri Teknolojiler Sempozyumu, 2009. (in Turkish).

[31] A. T. Çelebi and S. Ertürk, "Sonar imgelerinde ampirik kip ayrışımı ve morfolojik işlemler kullanarak hedef tespiti," 2010 IEEE 18th Signal Processing and Communications Applications Conference, pp. 760-763, 2010. (in Turkish).

[32] O. Sayli, "Hilbert-huang dönüşümü ile solunum seslerindeki üfürümün saptanmasi," 2014 22nd Signal Process. Commun. Appl. Conf. SIU 2014 - Proc., no. April, pp. 2194-2197, 2014.(in Turkish).

[33] H. Zhou, Z. Deng, Y. Xia, and M. Fu, "A new sampling method in particle filter based on Pearson correlation coefficient," Neurocomputing, vol. 216, pp. 208-215, 2016.

\section{BIOGR APHIES}

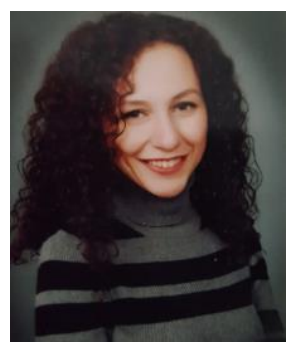

Rumeysa SELCUK was born in Sivas, Turkey, in 1993. She received his B.S degree from Electrical and Electronics Department of Engineering Faculty of University of Cumhuriyet, Sivas, in 2015. She has been currently a graduate student in Electrical and Electronics Engineering Department of Institute of Science and Technology of Gaziosmanpasa University, Tokat. She has been working as a Research Assistant in Department of Computer Engineering, Beykoz University Faculty of Engineering and Architecture.

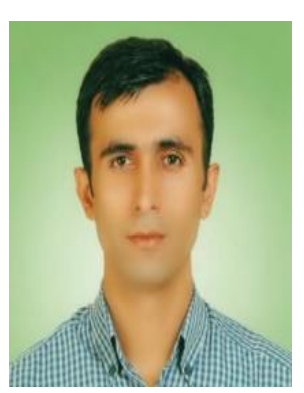

Zafer DOGAN was born in Tokat, Turkey, in 1974. He received the B.S. and Mc. S. degree in electrical education from Marmara University, Technical Education Faculty, Istanbul Turkey, in 1996 and 2009, respectively. He is currently a Assistant Professor in the Department of Electrical And Electronics Engineering, Tokat Gaziosmanpasa University Faculty of Engineering and Natural Sciences. His research interests are design of electrical machines and fault diagnosis in electrical machines. 